\title{
Assessing Professionalism among Residents: Peer and Self-assessment
}

\author{
Amira Salem ${ }^{1}$, Wagdy Talaat ${ }^{2}$, Mohamed H. Kamel ${ }^{3}$ and Nahla Hassan ${ }^{1 *}$ \\ ${ }^{1}$ Department of Medical Education, Faculty of Medicine, Suez Canal University, Egypt \\ ${ }^{2}$ Department of Pathology, Faculty of Medicine, Suez Canal University, Egypt \\ ${ }^{3}$ Department of Family Medicine, Faculty of Medicine, Suez Canal University, Egypt
}

\begin{abstract}
Objective: Assessing professional attitudes and behaviors as components of professionalism among residents at the Suez Canal University Hospital (SCUH).

Methodology: The study was a descriptive, cross sectional study, included residents at the Suez Canal University Hospital. A validated questionnaire to assess the professionalism components (attitude and behavior) was used. The first part of this questionnaire is a peer assessment through the Scale to Measure Professional Attitudes and Behaviors in Medical Education. The second part is Self-assessment questions from UMKC-SOM Climate of Professionalism Survey (University of Missouri-Kansas City School of Medicine). It contains 10 questions about professional behavior rated (mostly-often-sometimes-rarely).

Results: Residents are capable of consistently performing professionally across the domains of professionalism. However, variations across items suggest that professionalism is multifaceted, and the distribution of responses highlights some specific items where residents' performance could be improved.

Conclusion: Assessment of self and peer reported competences among residents at Suez Canal University Hospital showed that residents are capable of consistently performing professionally across the domains of professionalism. However, variations across items suggest that professionalism is multifaceted, and the Excellence subscale in a need for improvement.
\end{abstract}

Keywords: Professionalism; Peer assessment; Self-assessment; SMPABME

\section{Introduction}

Professionalism has been described by the American Board of Internal Medicine as "constituting those attitudes and behaviors that serve to maintain patient interest above physician self-interest [1]".

The word profession is derived from profess which means 'to proclaim something publicly'. Physicians profess two things: to be competent to help the patients and to have the patient's best interests in mind. Such commitment invites trust from their patients [1]. Professionalism is critical for physicians in order to provide optimum care and achieve better health outcomes [2].

Professionalism is based on the principles of primacy of patient welfare, patient autonomy, and social justice. It involves the following professional responsibilities such as: honesty, patient confidentiality, appropriate relations with patients, improving quality of care, improving access to care, just distribution of finite resources, commitment to scientific knowledge, maintaining trust by managing conflicts of interest, commitment to professional responsibilities [3].

In addition, professionalism is coming to the forefront as an essential element of graduate medical education as one of the six new core competency requirements of the Accreditation Council for Graduate Medical Education (ACGME). Professionalism is also integral to the widely endorsed Model of the Clinical Practice of Emergency Medicine. Program directors have now been charged with implementing the new core competencies in training programs and assessing the acquisition of these competencies in their trainees [4].

Society expects physicians to act professionally. In response to recent criticism regarding unprofessional behavior in medicine, some argue that improving medical professionalism can only occur through changes in teaching and assessing it [5].
Assessment of professionalism may also be performed at the program or institutional level. Consistent with current emphasis on measuring learning or performance outcomes in determining program quality, assessment data provide an important source of such evidence. As with individual learners, assessment may be viewed as having formative (program improvement) or summative (accreditation related) purposes, or both, and can include aggregation of individual assessment results or direct sampling of environmental attitudes and behaviors. It is important to consider the relationship between educational program objectives and learners' education experience (curriculum) in deciding upon assessment methods and content $[6,7]$.

Indeed, the absence of balanced assessment of professional attitudes and behaviors allows learners to develop misconceptions regarding their importance. Learners who are not assessed with regard to professionalism will logically assume that educators care less about this domain than knowledge or skill domains, which are assessed more thoroughly [6].

Although assessing professionalism has many challenges, ensuring growth in professionalism is impossible without measurement. The review of approaches to assess professionalism in medical education is that without valid assessment tools, questions about the efficacy of

*Corresponding author: Nahla Hassan, Department of Medical Education, Suez Canal University, Egypt, Tel: 2064 3200395; E-mail: nahlah_med@yahoo.com

Received October 05, 2015; Accepted October 10, 2015; Published October 30 2015

Citation: Salem A, Talaat W, Kamel MH, Hassan N (2015) Assessing Professionalism among Residents: Peer and Self-assessment. Intel Prop Rights. 3: 148. doi:10.4172/2375-4516.1000148

Copyright: ( 2015 Salem A, et al. This is an open-access article distributed under the terms of the Creative Commons Attribution License, which permits unrestricted use, distribution, and reproduction in any medium, provided the original author and source are credited. 
approaches to educating learners about professional behavior will not be effectively answered" [5].

The Accreditation Council for Graduate Medical Education (ACGME) lists 6 general competencies that physicians-in-training must possess before graduating from residency and fellowship training programs, one of which is "professionalism." In addition in defining professionalism, the ACGME lists attributes of professionalism including respect, compassion, integrity, responsiveness, altruism, accountability, commitment to excellence, sound ethics, and sensitivity to diversity. The American Board of Internal Medicine (ABIM), the American College of Physicians, and the European Federation of Internal Medicine, in the "Physician Charter," describe professionalism as "a foundation of the social contract for medicine" and lists 3 ethics principles and 10 "commitments," or attributes of professionalism [3].

\section{Components of professional attitudes and behaviors}

The next step of developing and measuring professional attitudes and behaviors in our educational programs is to determine their components. During the 2000 American Association of Colleges of Pharmacy (AACP) Teachers' Seminar, participants were asked to identify some professional attitudes and their corresponding behaviors. It is important to note that these attitudes and behaviors are appropriate for students as well as faculty members, although some may be more applicable to one party more than the other.

Similarly to these attitudes and behaviors, others have been described for health professionals - you do not need to "reinvent the wheel" when trying to identify professional attitudes and behaviors. For example, the American Board of Internal Medicine described these elements of professionalism for internal medicine physicians and physicians-in-training including:

- Altruism - Putting patients' best interests first.

- Accountability - To patients, to society, and to their profession.

- Excellence - Exceeding expectations and commitment to lifelong learning.

- Duty - Commitment to service in the community and professional organizations.

- Honor and integrity - Adhering to personal and professional codes, being fair, truthful, straightforward, and meeting commitments.

- Respect for others - All patients and their families, all colleagues and other health professionals [8].

So, this study was conducted with the aim of self and peer assessment of professionalism among residents at the Suez Canal University Hospital (SCUH).

\section{Methods}

A cross sectional descriptive study was conducted to Assess Professionalism among Resident doctors at the Suez Canal University Hospital. The Study population included the 113 junior and senior residents. The study population was selected by Comprehensive Sample where all the working residents in the Suez Canal University Hospital. Data collection Method was a self-administered questionnaire to assess the professionalism components (attitude and behavior).

The first part of the tool is a Scale to Measure Professional Attitudes and Behaviors in Medical Education. The Scale to Measure Professional Attitudes and Behaviors in Medical Education (SMPABME) consists of 12 items; each rated on a 4-item scale (Mostly-Often -SometimesRarely) [9].

The SMPABME obtains respondents' opinions about professionalism in their educational environment. Since the items ask the respondent to report on the behaviors of others (versus the respondent's own behavior) it can be used to obtain information about sensitive professionalism areas (e.g., deception) that respondents may be unwilling to report about themselves, thus it can give information about program-wide behaviors. The SMPABME may be used to gauge the effect of program-wide interventions that address professionalism areas.

Respondents used a four-point Likert type scale (mostly $=4$ often $=3$-sometimes $=2$-rarely $=1$ ) to answer the items. Items addressed unprofessional behaviors were reversed in their scoring so that high scores reflected more positive behaviors (rarely $=4$-sometimes $=3$ often $=2$-mostly $=1$ ) [10].

The peer assessment of Professionalism Questionnaire encompasses three domains:

\section{Excellence domain}

Which consists of 5 items with maximum score of 20, each item rated (mostly-often-sometimes-rarely) where "mostly" scored 4.

\section{Honor/Integrity}

Domain which consists of 4 items with maximum score of 16, Each item rated (mostly-often-sometimes-rarely) where "rarely" scored 4.

\section{Altruism/Respect}

Domain which consists of 3 items with maximum score of 12, Each item rated (mostly-often-sometimes-rarely) where "rarely" scored 4.

The second part of the tool is self-assessment questions from UMKC-SOM Climate of Professionalism Survey (University of Missouri-Kansas City School of Medicine). It contains 10 questions about professional behavior rated (mostly-often-sometimes-rarely).

The research protocol was approved by the Research and Ethics Committee at FOMSCU.

As for the analysis of quantitative data, information was presented in tabular and graphic forms. Data analysis was performed using the Statistical Package for the social sciences (SPSS version 13). Descriptive analysis; calculating the mean, median and mode. t- Test for comparing means of continuous data. P-value was set at $<0.05$ for significant results.

\section{Results}

The distribution of residents among three years was as follows:

21 residents (18.6\%) were in their first year of residency while 30 residents (26.5\%) were in their second year and 62 (54.9\%) residents were in their third year of residency (Table 1).

Table 1 shows that the mean score in the Excellence domain of professionalism among residents was 12.33 while their mean score in the Honor/Integrity domain was 13.07 and 8.7 in Altruism/Respect domain (Table 2).

Table 2 shows that first year residents performed peer assessment for Excellence domain behaviors with a mean score of 10.8 while the mean score in the second year residents was 12.3 and 12.9 in the third 


\begin{tabular}{|c|c|c|c|}
\hline Domains & $\begin{array}{c}\text { Mean score } \pm \\
\text { Standard deviation }\end{array}$ & Total score & Percent $\%$ \\
\hline Excellence score & $12.33 \pm 3.3$ & 20 & $61.65 \%$ \\
\hline Honor/integrity score & $13.07 \pm 2.8$ & 16 & $81.69 \%$ \\
\hline Altruism/respect score & $8.7 \pm 2.2$ & 12 & $72.5 \%$ \\
\hline Total professionalism score ${ }^{\dagger}$ & $34.08 \pm 6.4$ & 48 & $71 \%$ \\
\hline
\end{tabular}

tThe range of possible scores is 12 to 48 . Higher scores indicate more positive perceptions of professionalism and better result.

Table 1: The mean scores of Excellence, Honor/Integrity and Altruism/Respect domains of professionalism among residents in peer assessment $(n=113)$.

\begin{tabular}{|l|l|l|l|}
\hline Residency year & \multicolumn{2}{|l|}{ Score } & Altruism \\
\cline { 2 - 4 } & Excellence & Honor & $8 \pm 2.9$ \\
\hline $1^{\text {st }}$ year & $10.8 \pm 3.6$ & $9.6 \pm 3.9$ & $8.6 \pm 2.1$ \\
\hline $2^{\text {nd }}$ year & $12.3 \pm 2.8$ & $13.1 \pm 1.8$ & $8.9 \pm 1.8$ \\
\hline $3^{\text {rd }}$ year & $12.9 \pm 3.5$ & $14.3 \pm 1.5$ & $0.2(\mathrm{NS})$ \\
\hline p-value & $0.05(\mathrm{NS})$ & $0.001^{*}$ & \\
\hline
\end{tabular}

*Statistically significant difference.

NS: no significant difference.

Table 2: Relation between three domains scores and residency year in peer assessment $(n=113)$.

\begin{tabular}{|l|l|l|}
\hline Items & Excellence score & \\
\hline & $\mathbf{R}$ & p-value \\
\hline Honor score & 0.1 & $0.05(\mathrm{NS})$ \\
\hline Altruism score & 0.2 & 0.06 (NS) \\
\hline
\end{tabular}

NS: not statistically significant.

Table 3: Correlation between Excellence mean score and other domains scores in peer assessment $(n=113)$.

\begin{tabular}{|c|c|}
\hline Residency year & Score \\
\cline { 2 - 2 } & Self-assessment \\
\hline $1^{\text {st }}$ year & $29.4 \pm 4.9$ \\
\hline $2^{\text {nd }}$ year & $25.6 \pm 3.5$ \\
\hline $3^{\text {rd }}$ year & $29.5 \pm 4.9$ \\
\hline p-value & $0.001^{*}$ \\
\hline
\end{tabular}

\section{*Statistically significant difference.}

Table 4: Relation between scores of residents' self-assessment of professionalism competencies and residency year $(n=113)$

year. In Honor domain, the mean score of peer assessment in the first year residents was 9.6, while it was 13.1 in the second year, and 14.3 in the third year. In the Altruism domain, the first year residents assessed their peer with a mean score of 8 , while the mean was 8.6 in the second year, and 8.9 in the third year (Table 3 ).

Table 3 shows that there is no statistical significant difference between the mean score of Excellence domain and the two other domains (Honor and Altruism) (Table 4).

Table 4 shows that mean score of first year residents' selfassessment of their own professionalism is $(29.4 \pm 4.9)$ and it decreases in the second year residents to be $(25.6 \pm 3.5)$ then increase once again in the third year residents to be $(29.5 \pm 4.9)$. There was a statistical significant difference between residency year and the mean score of self-assessment $(\mathrm{p}<0.005)$ (Table 5).

Table 5 shows that there is a significant relation between displaying the professional behavior in peer assessment and in self-assessment ( $\mathrm{p}$ value $<0.005$ ).

\section{Discussion}

According to our study, the mean score percentage of peer assessment of residents' professionalism in all three domains was estimated to be $71 \%$ and this result was lower than the mean score percentage that obtained by Bo Qu, Yu-hong Zhao and Bao-zhi Sun who conducted a study about multisource feedback to assess professionalism, interpersonal and communication skills by China Medical Board for resident physicians in China and showed that mean score percentage of residents' professionalism through peer assessment was $97 \%$ [11], while Arnold et al. [12] who conducted a study in five institutions in northeast region of United State and Jennifer et al. [13] at the University of Missouri-Kansas City School of Medicine reported mean score percentages of $77.4 \%$ and $75.08 \%$ respectively.

The lower mean score percentage in our study comparable to other studies could be explained by the increased workload of residents that may affect their professional behaviors, also lack of formal and structured curriculum or working program addressing professionalism as an integral competency of the today's doctors could be considered an important factor in this regard.

Residents' assessment related to professionalism of their peers indicated that residents demonstrate professional behaviors which varied between three domains (Excellence, Honor/Integrity and Altruism/Respect). However some problematic areas were identified, particularly in the Excellence domain where it means score percentage was estimated to be $61.65 \%$. This finding was less than that of Gillespie [14], in a similar study conducted at New York University School of Medicine where the mean percent score was $78.1 \%$ and in another study by Arnold [12] where the mean percent score $76.78 \%$.

The lower mean score percentage of the Excellence domain of professionalism in our study could be attributed to deficiency in the professional behaviors and this could be explained by absence of the role modeling for the residents to follow. It also indicated that the climate in some clinical settings requires further attention and also in a need for improvement.

On the other hand, professionalism at the Honor/Integrity domain mean score percentage was estimated to be $81.69 \%$. In the study of Gillespie [14] the mean score percentage of professionalism at the Honor/Integrity domain was $77.7 \%$. The high mean score percentage of our study at this domain showed that our residents have higher standards of acceptable behaviors as they avoid violating one's personal or professional codes.

As regard the domain of Altruism/Respect, the estimated mean score percentage was $72.5 \%$. In Arnold [12] it was $70 \%$. The higher percent in our study could be attributed to the acceptable deal of respect our residents paying to patients, patients' families, colleagues, and assistants.

Professionalism of residents as evaluated by their peers was found to be progressively increasing from the first year residency to third year as evidenced by the increase in the mean scores as the first year residents performed peer assessment for Excellence domain behaviors with a mean score of 10.8 while the mean score in the second year residents was 12.3 and 12.9 in the third year. In Honor domain, the mean score of peer assessment in the first year residents was 9.6 and 13.1 in the second year and 14.3 in the third year, while in Altruism domain the 


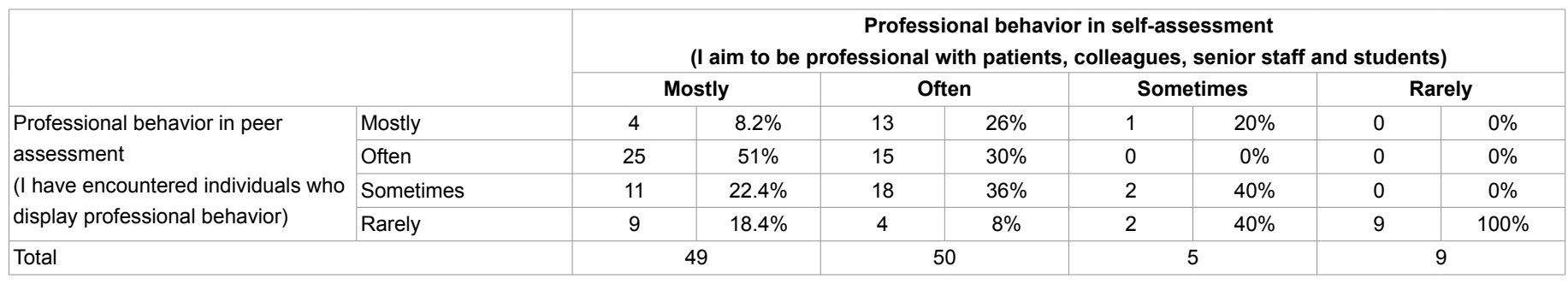

Chi square $=51.2$ p-value $=0.001^{*}$ (statistically significant association)

Table 5: Relation between displaying professional behavior in peer assessment and self-assessment $(n=113)$.

first year residents assess their peer with a mean score of 8 and 8.6 in the second year and 8.9 in the third year. This finding was consistent with that of Van Rosendaal [15], who found that senior residents were interested in peer evaluation than junior residents and in the same time their level of professionalism was evaluated to be better.

According to the above results, these findings indicate that the judgment abilities of the residents increase with the years of residency and experience and the long contact with the peers leads to increase in the perception of the professional behaviors of residents in the three domains of professionalism.

There was a statistically significant difference between the residency year and the level of professionalism on Honor domain while in the study conducted by Arnold [12] there was a statistically significant difference between the residency year and level of professionalism on the Excellence domain [13]. This finding of our study is supported by the high mean score percentage of professionalism on the Honor domain.

Overall, our assessment of peer reported competences among residents at Suez Canal University Hospital showed that residents are capable of consistently performing professionally across the domains of professionalism. However, variations across items suggest that professionalism is multifaceted, and the distribution of responses highlights some specific items where residents' performance could be improved. Our findings suggest that measuring professionalism in this way (professional attitudes and behaviors through peer assessment) provides intriguing and potentially actionable information. This study provides some direction for moving us closer to effective and constructive assessment of professionalism and toward being able to identify the ways in which the learning environment may shape residents' professional development.

Regarding residents' self-assessment in our study, the mean score percentage of resident's self-assessment of professionalism was $71 \%$, while Jennifer et al. at the University of Missouri-Kansas City School of Medicine and Bo Qu, Yu-hong Zhao and Bao-zhi Sun who conducted a study about multisource feedback to assess professionalism, interpersonal and communication skills by China Medical Board for resident physicians in China reported mean score percentages of $75.01 \%$ and $95.8 \%$ respectively $[11,13]$ and this indicated that our residents may have higher expectations of themselves than residents in the other study do.

The results of resident's self-assessment in our study can be explained in view of the well-known phases of learning cycle. Residents in their first year are unconscious incompetent accordingly their selfassessment was higher than second year residents who are on the phase of conscious incompetent. In the third year of their residency, residents become more conscious competent which increase their self-assessment. There was a statistically significant difference between residency year and the mean score of self-assessment $(\mathrm{p}=0.001)$.

Also our study stated that residents' self-assessment of professionalism is related to their reporting of professionalism for their peers as there was a significant relation between behaving in a professional manner either in peer assessment or self-assessment ( $p$ - value $=0.001)$. This finding was consistent with that of Brownell and Cote and also with that of Gillespie et al. $[14,16]$. These findings indicated that professionalism is highly related to residency year, number of working hours. It also emphasizes the impact of peer assessment and feedback.

\section{Conclusion}

Overall, our assessment of self and peer reported competences among residents at Suez Canal University Hospital showed that residents are capable of consistently performing professionally across the domains of professionalism. However, variations across items suggest that professionalism is multifaceted, and the distribution of responses highlights some specific items where residents' performance could be improved. A structured course in professionalism with valid and reliable assessment methods for residents is recommended.

\section{Acknowledgement}

The authors would like to thank the residents at Suez Canal University Hospital who participated in this research for their cooperation.

\section{Conflict of interest}

The authors declare that they have no conflict of interest.

\section{References}

1. Pellegrino ED (2002) Professionalism, Profession and the Virtues of the Good Physician. Mt Sinai J Med 69: 378-384.

2. Symons AB, Swanson A, McGuigan D, Orrange S, Akl EA (2009) A tool for self assessment of communication skills and professionalism in residents. BMC Med Educ 9: 1.

3. Project of the American Board of Internal Medicine Foundation (2002) American College of Physicians-American Society of Internal Medicine Foundation, European Federation of Internal Medicine Medical professionalism in the new millennium, a physician charter, Ann Intern Med 136: 243-246.

4. Larkin GL, Binder L, Houry D, Adams J (2002) Defining and evaluating professionalism: a core competency for graduate emergency medicine education. Acad Emerg Med 9: 1249-1256.

5. Lynch DC, Surdyk PM, EiserAR (2004) Assessing professionalism: a review of the literature. Med Teach 26: 366- 373.

6. Hawkins RE, Katsufrakis PJ, Holtman MC, Clauser BE (2009) Assessment of medical professionalism: Who, what, when, where, how, and ... why?. Med Teach 31: 348-361.

7. Arnold L (2002) Assessing professional behavior: yesterday, today, and tomorrow. Acad Med 77: 502-515. 
Citation: Salem A, Talaat W, Kamel MH, Hassan N (2015) Assessing Professionalism among Residents: Peer and Self-assessment. Intel Prop Rights. 3: 148. doi:10.4172/2375-4516.1000148

Page 5 of 5

8. Kirk LM (2007) Professionalism in medicine: definitions and considerations for teaching. Proc (Bayl Univ Med Cent) 20: 13-16.

9. Hammer PD (2000) Professional Attitudes and Behaviors: The "A's and B's" of Professionalism. Am J Pharm Educ 64: 455-464.

10. Accreditation Council for Graduate Medical Education. Common program requirements: general competencies.

11. Bo Qu, Yu-hong Zhao, Bao-zhi Sun (2012) Assessment of Resident Physicians in Professionalism, Interpersonal and Communication Skills: a Multisource Feedback. Int J Med Sci 9: 228-236.

12. Arnold E, Blank L, Race K, Cipparone N (1998) Can professionalism be measured? The development of a scale to be used in the medical environment. Acad Med 73: 1119-1121.
13. Quaintance JL, Arnold L, Thompson GS (2008) Development of an instrument to measure the climate of professionalism in a clinical teaching environment. Acad Med 83: S5-S8.

14. Gillespie C, Paik S, Ark T, Zabar S, Kalet A (2009) Residents' perceptions of their own professionalism and the professionalism of their learning environment. J Grad Med Educ 1:208-215

15. Van Rosendaal GMA, Jennett PA (1992) Resistance to peer evaluation in an internal medicine residency. Acad Med. 67: 63 .

16. Ginsburg S, Regehr G, Hatala R, McNaughton N, Frohna A, et al. (2000) Context, Conflict, and Resolution: A new conceptual framework for evaluating professionalism. Acad Med 75: S6-S11. 